\title{
Ciudadanía igualitaria: del Estado social a una democracia de propietarios
}

Héctor David Rojas Villamil ${ }^{*}$

\section{Las condiciones materiales para el funcionamiento de la democracia}

Un sistema capitalista liberal le atribuye una importancia fundamental al reconocimiento y protección formal de un conjunto de libertades políticas de las que debe gozar toda la ciudadanía. La libertad de conciencia, de expresión, de prensa y de asociación, entre otras, crean áreas de no interferencia que limitan el ejercicio de autoridad del Estado y las conductas ciudadanas. Este sistema permite y encuentra justificadas y grandes desigualdades de ingresos, riquezas y poder entre los ciudadanos, siempre y cuando estas se deriven de las interacciones no viciadas por fraude o coerción en un mercado competitivo.

La dificultad con este sistema es que la esfera política en la que se reconoce la igualdad formal de los ciudadanos no está aislada a la esfera económica de los mercados. Aquellos que debido a su talento, mayor dedicación, mejor posición inicial o simple suerte resultan más exitosos en su vida mercantil pueden utilizar las ventajas económicas para influir en mayor medida en los resultados democráticos de la esfera política, lo que les permite utilizar el sistema institucional del Estado para proteger y promover sus intereses. En un ambiente de dominación y dependencia económica, al ejercicio de las libertades políticas le falta valor para aquellos más vulnerables. De forma más específica, las ventajas económicas invaden la esfera pública debido a que el sistema permite que se financien campañas, que se controlen o monopolicen los

\footnotetext{
* PhD. en Filosofía y M.A. en Teoría Jurídica, de la University of Bristol (Reino Unido); abogado de la Universidad Externado de Colombia y filósofo de la Universidad Libre de Colombia.
} 
medios de comunicación, y que se desplieguen estrategias de lobby para que el poder público sirva unos objetivos específicos de autointerés.

Como lo apunta Daniels, en el capitalismo del laissez-faire se promueve una idea de libertad que puede ser vista como arbitraria e injustificada (Daniels 1975, p. 257). La libertad supone un poder de no ser interferido en el ejercicio de una acción. Respecto a las libertades políticas, el capitalismo protege su ejercicio de interferencias como la coerción o censura estatal; no obstante, aquellos obstáculos que provienen de factores económicos no son considerados como violaciones a las referidas libertades. Según esta visión, si un ciudadano es obstruido violentamente cuando intenta acceder al puesto de votación sufre una afectación a su libertad, pero si simplemente carece de recursos para desplazarse hasta la urna su libertad permanece incólume. La dificultad es que esta distinción entre los obstáculos que son considerados como limitantes de la libertad y aquellos que no es arbitraria, es decir, no se fundamenta en una razón justificada.

De forma más precisa, cuando hay una limitación que proviene de los resultados de los mercados competitivos esta forma de capitalismo afirma que existe una deficiencia en los medios para ejercer la libertad, pero no una violación a la libertad. Si una persona es demasiado vulnerable en sus condiciones socioeconómicas para ejercer sus derechos y poderes legalmente reconocidos, no carece de libertad sino de las precondiciones para ejercerla. De acuerdo con esta posición, la función del Gobierno debe ser proteger la libertad, pero debido a que los obstáculos consistentes en la falta de recursos materiales no son consideradas como interferencias, el Estado debe abstenerse de implementar medidas redistributivas diferentes a aquellas necesarias para mantener los mercados libres y competitivos; más aun cuando dichas medidas implican una injerencia en los resultados de las transacciones libres de los ciudadanos en la esfera del mercado.

Cohen (2011, p. 174) ha criticado esta argumentación afirmando que está basada en una visión reificada del dinero. Ciertamente, hay obstáculos para realizar ciertas acciones que no implican una afectación a la libertad. Si carezco de las condiciones físicas para competir con Hussain Bolt no sufro una vulneración a mi libertad, a pesar de que existen obstáculos para que realice una acción, como mi mal estado físico y mi predisposición genética. No obstante, afirma Cohen, el dinero no puede equipararse a un obstáculo como la falta de capacidad física, motriz o de intelecto.

La función del dinero, entre otras, es operar como un instrumento a través del cual se estructura un sistema de libertad dentro de una sociedad (Cohen, 2011, p. 176). Si intento acceder a bienes o servicios que son propiedad de otros seré normalmente objeto de interferencia en mi acción a través del aparato represivo del Estado. El dinero puede remover dicho obstáculo y permitirme acceder a mis metas; el dinero no es una "cosa" sino el mecanismo estructural a través del cual 
se administra y distribuye la libertad en una sociedad. La carencia de dinero no equivale a la falta de una habilidad para ejercer la libertad, sino que representa en sí misma una carencia de libertad. La diferencia entre el colado en un bus y el que pagó el pasaje es que el primero carece de la libertad para permanecer en su silla sin injerencia de terceros.

La crítica de Cohen y Daniels se dirige en contra de la idea de que el capitalismo del laissez-faire es un sistema que da prioridad a la libertad sobre consideraciones redistributivas que instrumentalizan y denigran a las personas al permitir que el Estado interfiera con los resultados de las transacciones libres entre adultos competentes en el mercado. En realidad, dicho sistema, con su tendencia a la concentración y a la disparidad, limita en gran medida los radios de acción donde los más vulnerables pueden actuar, los excluye del acceso a los bienes básicos para la subsistencia y los marginaliza.

\section{Las libertades políticas y su valor}

Rawls (1993) no aceptó el argumento según el cual la carencia de recursos económicos equivale a una interferencia directa con la libertad, pero no es indiferente al peligro identificado. Rawls hace una distinción entre las libertades y su valor (p. 356). En el primer caso, se hace referencia a una estructura de poderes y prerrogativas formales que definen un área en la que la acción no puede ser interferida por terceros. En el segundo caso se hace mención a la utilidad que tiene para un individuo poseer dichas garantías formales. Dicha utilidad se puede ver afectada por la distribución de ventajas materiales especificadas en un índice de bienes primarios.

Rawls considera que el hecho de que su teoría afirme que en una sociedad bien ordenada tiene que darse primacía a un sistema adecuado de libertades al que todos deben tener acceso por igual no significa que esas garantías sean puramente formales. Debido a que su teoría también incluye un principio de diferencia, según el cual solo están justificadas las desigualdades sociales cuando ellas redundan en un mejoramiento de la situación de los peor situados, el valor de las libertades se encuentra garantizado, ya que la esfera socioeconómica se encuentra regulada de forma justa.

En su teoría, las libertades políticas ocupan un lugar especial en cuanto requieren que el sistema institucional garantice su valor equitativo. La ciudadanía igualitaria exige que las reglas de juego de la sociedad estén estructuradas de forma tal que las personas consigan ejercer adecuadamente sus libertades políticas y así poder influir en igual medida en los procedimientos democráticos con independencia de su situación económica. Para aislar la esfera económica de la política se pueden adoptar 
estrategias como establecer la financiación pública de las campañas políticas, imponer restricciones a las contribuciones por parte de particulares y personas jurídicas, garantizar el acceso igualitario a medios y limitar las concentraciones de riqueza de acuerdo con el principio de diferencia.

La importancia que Rawls (1993, p. 361) atribuye a la igualdad democrática puede ilustrarse con su crítica a dos fallos de cortes de Estados Unidos en la que se desconoció dicho principio. En el caso de First National Bank vs. Belloti se anuló una ley criminal de Massachussets que imponía una prohibición sobre los bancos y corporaciones de financiar o costear campañas en procesos de referendo, salvo si se veían directamente afectadas en su patrimonio u operación por la decisión en cuestión. El segundo caso es el de Buckley vs. Valeo en el que se declaró inconstitucional una enmienda que buscaba imponer límites a los gastos electorales y a las contribuciones a las campañas. En estos fallos se argumentó que imponer un límite a la financiación equivale a una impermisible interferencia con la participación política y con el discurso público. Rawls rechazó esta argumentación y afirmó que es competencia del Congreso tomar medidas que garanticen el valor equitativo de las libertades políticas y evitar que la esfera pública se constituya en un escenario donde las decisiones se vean fuertemente influidas por los recursos económicos que los grupos de interés estén dispuestos a utilizar para moldear el ordenamiento jurídico convenientemente. El punto de Rawls es que en sus principios de justicia se formula una cláusula sobre el valor equitativo de las libertades políticas que justifica la limitación de otras libertades cuando sea necesario para preservar la ciudadanía igualitaria.

Esta preocupación por la igualdad democrática ha llevado a diversos autores a considerarla como el fundamento de la justicia distributiva (Anderson, 1999). Según esta posición, la igualdad es un ideal político y relacional que aplica exclusivamente a contextos donde existen asociaciones políticas que ejercen autoridad pública sobre una ciudadanía. Debido a que una sociedad así descrita debe constituirse en un sistema justo de cooperación social, su principio rector es el de la reciprocidad. Este principio exige que la estructura institucional pública sea diseñada en términos aceptables para todos los ciudadanos y es por este motivo que existe una carga de justificación sobre todas las inequidades que dicho sistema genere. Así, desde esta perspectiva, la justicia distributiva tiene por objeto determinar qué tendencias distributivas tiene que generar un sistema institucional para obtener resultados que sean consistentes con el ideal de una sociedad de iguales. En dicha sociedad cada miembro tiene un estatus paritario y tiene un derecho a influir en igual medida en las decisiones públicas que se toman en nombre de la asociación política.

De acuerdo con la igualdad democrática, el objeto de la justicia distributiva no es obtener un determinado resultado final de porciones distributivas entre los ciudadanos ni generar unos patrones fijos de acceso a bienes y servicios. La 
distribución está exclusivamente justificada por su rol en garantizar que los ciudadanos preserven entre sí relaciones paritarias en la esfera política. Qué tan igualitaria deba ser una sociedad dependerá del rol de la riqueza en la vida política y del impacto de las desigualdades sociales en el ejercicio de la ciudadanía. Por supuesto, el acceso a un umbral mínimo humanitario de bienes y servicios es necesario para actuar en un plano de igualdad con los demás, pero la garantía de estos estándares básicos puede no ser suficiente, pues individuos que no tengan carencias humanitarias pueden verse dominados políticamente por otros ciudadanos mejor situados. Este argumento busca establecer cuál es el fundamento de la justicia distributiva, es decir, determinar los motivos que podemos tener para requerir más igualdad material entre ciudadanos.

Se debe notar que la discusión versa sobre un punto fundamental en la justificación de las agendas más conservadoras en materia política y económica; determinar si el dinero es constitutivo de la libertad o solo un medio para ejercerla es importante, porque busca arrebatarle la idea de libertad al liberalismo clásico, que busca ubicarla como el valor fundamental que justifica los mercados y el rechazo a la interferencia estatal. El argumento refuta la idea de que las políticas distributivas atentan contra la libertad humana e instrumentalizan a los individuos para mantener un patrón de distribución fijo en la sociedad y de esta manera se desconocen los resultados de las transacciones libres entre ciudadanos. Nozick, por ejemplo, equipara la tributación a trabajo forzado pues una persona, para satisfacer sus preferencias, debe laborar el número de horas necesarias para acceder a ellas y un número adicional para pagar el tributo (Nozick 1974). Uno de los problemas de este argumento es que desconoce que el ejercicio de la libertad supone no solo una capacidad para deliberar y realizar actos voluntarios, sino que requiere que esa facultad de volición sea ejercida en un contexto adecuado que dote a nuestras decisiones de valor y significado. Los resultados acumulados de las transacciones del mercado pueden ubicar a muchos ciudadanos a lo largo de las generaciones en circunstancias que privan de valor toda decisión que puedan tomar, como por ejemplo morir de hambre o vender su fuerza de trabajo por un monto paupérrimo (Rawls, 1993, p. 23). La intervención del Estado al establecer un salario mínimo más que una interferencia en las decisiones libres de patronos y trabajadores es el reconocimiento de que el extremo vulnerable de la relación merece ser ubicado bajo condiciones en las que el ejercicio de su libertad sea valioso. Esto muestra que las políticas sociales y redistributivas no buscan sacrificar la libertad en aras de preservar otros valores como la igualdad; por el contrario, ven con sospecha el tipo de libertad que los mercados prometen y buscan preservar las circunstancias apropiadas para que las decisiones humanas estén llenas de dignidad y significado para quienes las toman. 


\section{La igualad democrática ante el fenómeno de la gobernanza}

La igualdad democrática parte de la idea de que las condiciones socioeconómicas de trasfondo bajo las cuales las instituciones del Estado operan son importantes para un adecuado ejercicio de las libertades democráticas y para garantizar su valor equitativo. No obstante, esta posición pone el énfasis en la esfera política como el área formal de la deliberación pública y de la toma de decisiones sobre el ejercicio del poder público, y deja de lado el hecho de que el autogobierno y las reglas que rigen a la sociedad trascienden esas instancias oficiales de las instituciones democráticas. Las políticas públicas se moldean, no solo a través de una burocracia estatal sujeta al mandato constitucional de proveer servicios públicos a los ciudadanos, sino también a través de grupos de ciudadanos no oficialmente institucionalizados que tienen una capacidad significativa de influencia y poder. Es por esto que enfocarse exclusivamente en la paridad democrática a nivel institucional del Estado no asegura que la vida en sociedad estará libre de dominación y dependencia. Un ciudadano puede no quejarse de su estatus igualitario como ciudadano, puede encontrar que tiene un nivel de influencia adecuado sobre las decisiones públicas, o pensar que el foro público ofrece oportunidades para la deliberación libre y respetuosa de las minorías, e incluso puede tener la convicción de que lo público no es subyugado por el poder económico. Sin embargo, es posible que dicho ciudadano esté inconforme al encontrar que esa ciudadanía igualitaria solo le da un control, que ejerce en conjunto y con paridad, bajo el reconocimiento de que ciertos áreas de regulación y gobierno escapan a la esfera pública y de que las decisiones democráticas tienen que acoplarse a las exigencias de grupos o formas no institucionales de poder. Esto no significa que esta dispersión del poder, más allá del ámbito meramente institucional, sea algo necesariamente negativo. La dificultad está en que afuera de este marco las relaciones de poder que definen las reglas comunes de interacción resultan impredecibles y no hay garantías de que no causarán exclusión o dominación.

Más precisamente, el fenómeno de la gobernanza resulta inquietante para esta aproximación. En primer lugar, porque revela que existen redes entre actores y grupos de poder que están involucradas en la toma de decisiones sobre políticas constituidas precisamente por las condiciones socioeconómicas imperantes en la sociedad. La preocupación por la forma como los resultados agregados del mercado pueden erosionar las condiciones para el ejercicio de la libertad se traslada así a instancias de decisión, monitoreo y evaluación que reflejan el pulso de poder entre grupos de poder horizontalmente ubicados. En segundo lugar, muestra que la administración pública ya no responde únicamente a un modelo jerárquicamente organizado de órdenes que emergen de la autoridad del Estado dotada de legitimidad democrática, sino que responde a formas de negociación, articulación y apoyo entre diversos agentes. 
Antes de desarrollar estos puntos es importante iniciar con una definición de gobernanza. Dicho término está lleno de ambigüedades y no se encuentra una definición unívoca en la literatura. En una forma general, que sirve a los propósitos de este escrito, la gobernanza puede ser entendida como el conjunto de procedimientos, relaciones, sistemas y procesos a través de los cuales se toman de decisiones, se ejecutan, evalúan y se expiden regulaciones bajo mecanismos de negociación entre diversos actores interdependientes, de índole civil o estatal, que deben coordinar su actuar y cooperar con miras a obtener un resultado o propósito público. La idea de gobernanza surge del entendimiento de que la formulación y ejecución de políticas públicas o la realización de fines sociales no puede sujetarse exclusivamente al ejercicio de autoridad del Estado que, a través de su aparato burocrático y con sujeción al principio de legalidad, debe buscar materializar los valores y principios constitucionales, ni tampoco al mecanismo de la mano invisible del mercado que permite la obtención de resultados eficientes si operan de forma libre y competitiva (Sørensen, 2007, p.12). La gobernanza se fundamenta en el reconocimiento de que entre estos dos extremos existen cadenas de gobierno o poder que no son reducibles a la mera ejecución por parte de la administración pública ni a las fuerzas del mercado. Según Sørensen esas cadenas o redes de gobernanza son formas de articulación entre actores que son interdependientes (en razón a los recursos y capacidades que poseen), que son operacionalmente autónomos, es decir, se autorregulan e interactúan a través de negociaciones con miras a realizar una finalidad pública en la cual tienen interés (Sørensen, 2007, p. 9). Puede pensarse, por ejemplo, que para proveer un acceso integral a la justicia se requiere la articulación entre las redes de consultorios jurídicos de las Facultades de Derecho, las cámaras de comercio, comisarías de familia, autoridades indígenas y la rama judicial, entre otros. Se trata entonces de una oferta que, buscando realizar valores constitucionales, debe apoyarse en cadenas de gobernanza para articular la toma de decisiones y la ejecución de acciones efectivas. Igualmente, piénsese en rol de la administración cuando ante un desastre natural debe articular su acción con la de la cruz roja y otras organizaciones humanitarias sobre las que no tiene jurisdicción.

Ahora bien, el riesgo ciertamente está en que los intereses que mueven a los diferentes actores pueden llevarlos a presionar para que la política pública adopte la estructura que sea conveniente a grupos específicos de poder (Koliba, 2010, p. 25). La preocupación por la igualdad democrática parece morigerarse cuando se observa que es en las redes de gobernanza y no en la esfera pública institucionalizada por los mecanismos democráticos donde la disparidad resulta decisiva para determinar la toma de decisiones en materias de interés público. De acuerdo con esta visión, si se buscan políticas igualitarias es con miras a evitar la dominación en las redes de gobernanza y solo de forma derivada en la esfera política que refleja esas relaciones de poder. 
Independientemente de la perspectiva que se adopte, la igualdad democrática sigue siendo un ideal que tiene una importancia autónoma que no se limita simplemente a la paridad aproximada en el poder de facto entre los miembros de la sociedad. La gobernanza muestra que la posibilidad de adoptar, ejecutar y monitorear determinadas políticas públicas puede depender de redes en las que participan particulares, organizaciones, empresas, multinacionales, entre otros. No obstante, dentro de las múltiples relaciones de poder que existen en la sociedad (por ejemplo, la sujeción de un trabajador a su patrono, de un consumidor frente a un proveedor de servicios, la de un pastor frente a sus fieles) la relación del ciudadano con el poder público tiene una característica especial. Si bien en todas ellas puede existir dominación, el Estado opera a través de un sistema jurídico que es impuesto bajo una pretensión de autoridad que requiere una justificación pública. El derecho no solo impone deberes de conducta, sino que además afirma hacerlo con autoridad. Esta última, en sentido evaluativo, es el poder de cambiar el conjunto de obligación y derechos de un individuo y se diferencia del simple poder de facto de someter a alguien a la voluntad propia. Un ladrón puede darme un mandato de que le entregue un millón de pesos; lo mismo puede hacer la Dirección de Impuestos y Aduanas Nacionales (DIAN). Aunque ambos estén en la posición de ejercer mecanismos coercitivos para obligarme a dar cumplimiento a la orden, solo la burocracia estatal reclama un derecho legítimo a imponer un deber sobre mí atribuyéndose la potestad de exigirlo en caso de incumplimiento. El vecino puede decirle al hijo del vecino que no moleste y se quede sentado; lo mismo puede hacer el padre. Solo el segundo emite la orden bajo la convicción de poder imponer un deber y de darle razones legítimas de acción al menor. La importancia de las relaciones ciudadanas y la preocupación por preservar la paridad en ellas está en que el ordenamiento jurídico debe justificar esa pretensión de autoridad y esa justificación debe ser, según la igualdad democrática, el producto de procedimientos públicos, trasparentes y democráticos entre ciudadanos que codeliberan. Podemos pensar hipotéticamente en un Estado autoritario en el que un dictador ha logrado el establecimiento y el mantenimiento de redes de gobernanza en la que se han dispersado las formas interpersonales de dominación en los ámbitos privados y mercantiles. En dicha situación, los defensores de la igualdad democrática objetarán que el ejercicio del poder público no protege las libertades públicas ni garantiza un foro público para la toma de decisiones políticas; igualmente, señalarán que no todas las disparidades en las redes de gobernanza son objetables en cuanto algunas de ellas no tienen un impacto en el ejercicio paritario de la ciudadanía.

Por lo anterior, el rol del Estado dentro de las redes de gobernanza sigue teniendo un lugar preponderante y tiene una dimensión justificativa que no se reduce al plano de las relaciones e interacciones en la sociedad civil. Ante este panorama, la pregunta por la forma de organización estatal que deberían adoptar los Estados 
para realizar un ideal de igualdad democrática resulta de gran importancia, con miras a establecer estándares institucionales que eviten que la gobernanza erosione el valor equitativo de las libertades políticas o que devalúe el foro democrático como instancia de toma de decisiones de índole política. En la siguiente sección se presentan las respuestas de Rawls (2001) a este interrogante.

\section{La ciudadanía igualitaria y los tipos de Estado}

Al momento de considerar las formas de organización estatal que podrían instanciar sus principios de justicia, Rawls se mostró crítico del Estado capitalista del laissez-faire (Rawls, 2001, p. 137). Teniendo como meta la eficiencia en los mercados, es un sistema indiferente a la redistribución social, lo que aminora el valor equitativo de las libertades políticas y la igualdad de oportunidad. Igualmente, un socialismo de Estado, entendido como un sistema en el que los medios de producción están colectivizados, los recursos productivos son ubicados de acuerdo con un plan económico centralizado y los procesos democráticos no son utilizados para la toma de decisiones públicas, sería un arreglo social incapaz de instanciar los principios de justicia, en razón a que no existe un reconocimiento formal de las libertades y derechos básicos, sobre todo aquellos que empoderan a los ciudadanos en la esfera política (Rawls, 2001, p. 138).

Debido a la importancia que Rawls (2001, p. 139) atribuye a la ciudadanía igualitaria, no resulta sorprendente que haya rechazado estas formas de organización estatal. Por el contrario, sus críticas al Estado social o de bienestar han sido objeto de grandes debates en la literatura reciente. Este modelo de Estado es visto por muchos como la estructura institucional que más ha avanzado en la causa de la justicia y como el objetivo ideal hacia el que deben tender las asociaciones políticas. Antes de explicar los motivos que fundamentan esta crítica, hay que establecer cuáles son las propiedades de este modelo. Valga aclarar que las formas de Estado aquí descritas son arquetipos ideales que busca especificar los rasgos esenciales de cada uno de ellos. En la realidad, estos modelos pueden contener fórmulas híbridas o funcionar de forma imperfecta; por lo tanto, no estamos hablando de ningún Estado en particular, sino de la estructura ideal de los mismos.

Los Estado de bienestar se caracterizan porque en ellos los mercados no son el único mecanismo para determinar la distribución de las ventajas sociales. Por el contrario, dicha forma de organización estatal establece una canasta de servicios públicos y bienes básicos a la que todas las personas deben tener acceso, no en virtud del éxito que el talento o la suerte les depare en sus interacciones mercantiles, sino de 
la dignidad humana que les es inherente. Se necesita que haya una garantía de seguridad social en la que, a través de un fondo financiado por cargas impuestas a los trabajadores, a los patronos u otras formas de tributación, se cubran las necesidades básicas de la comunidad. La canasta contendrá normalmente acceso al servicio de salud, educación básica, pensiones, seguro de desempleo, vivienda y cobertura del mínimo vital.

Weale señala que el tipo de distribución en este modelo de Estado es principalmente horizontal y no vertical (Weale, 2013, p. 46). Esto quiere decir que se distribuye la riqueza que produce una persona a lo largo de su ciclo vital, dándole asistencia en sus etapas no productivas (infancia, enfermedad, vejez o desempleo), la cual es financiada con sus contribuciones al sistema durante sus momentos económicamente activos. De esta forma, no se trata de una distribución de una clase social a otra, sino de utilizar la mediación institucional del Estado para lograr que las personas no estén desprovistas en sus etapas más vulnerables de los recursos necesarios para subsistir y desarrollar sus capacidades, teniendo la carga de hacer aportes cuando estén en condiciones apropiadas para hacerlo.

Esta forma de Estado está fundamentada en dos principios: el de contribución y el de solidaridad. El primero supone que al tratase de redistribuciones a lo largo del ciclo vital de las personas, estas deben contribuir al fondo común durante sus etapas productivas para garantizar la sostenibilidad del sistema (Weale, 2013, p. 48). El segundo exige que haya una cobertura a toda la sociedad, y esto requiere que el monto de las contribuciones no corresponda estrictamente a un cálculo actuarial del riesgo personal, de forma que exista un régimen de solidaridad y apoyo a los más vulnerables.

Rawls (2001, p. 139) consideró que las políticas del Estado social resultan insuficientes para proteger el valor igualitario de las libertades políticas, la igualdad de oportunidad y la reciprocidad como fundamento de la igualdad. En primer lugar, si bien es cierto que el Estado de social protege la igualdad formal en el ejercicio de las libertades políticas, también permite que las reglas de juego de la democracia se desplieguen bajo condiciones de gran disparidad, en las que las grandes concentraciones de riqueza pueden interferir con la igualdad ciudadana. La esfera económica termina invadiendo el campo político para promover los intereses de ciertos sectores y generando una dominación sobre los más vulnerables. Una vez todos alcanzan un estándar de vida mínimo de subsistencia, las desigualdades dejan de ser objetables e incluso es válido que se conformen monopolios. Esta aproximación pasa por alto el hecho de que no somos únicamente seres biológicos, sino también políticos, y que existe una permanente carga por parte del Estado de justificar el ejercicio del poder público, con lo cual se muestra que existe una real paridad entre ciudadanos. 
Siguiendo al economista James Meade, Rawls afirmó que el modelo de Estado que podría materializar de mejor manera los principios de justicia por él propuestos sería una democracia de propietarios. Dicho sistema tiene tres aspectos que caracterizan esos principios: 1) es un sistema en el que existe una amplia dispersión del capital, tanto en lo referente a los medios de producción, como a la capacitación y preparación técnica de los ciudadanos (capital humano); 2) se imponen límites a la transmisión de ventajas económicas intergeneracionales por medio de tributación a las herencias y donaciones; 3 ) se establecen garantías para evitar que el poder económico de los particulares pueda transformarse en mayor preponderancia en los procedimientos democráticos, a través de la financiación pública de las campañas y el acceso igualitario a los medios de comunicación.

La democracia de propietarios se diferencia del Estado social porque no busca redistribuir los ingresos de los ciudadanos con miras a proveer un mínimo humanitario a los más vulnerables, sino que pretende establecer unas reglas de trasfondo que dispersen ampliamente la propiedad productiva (y evita así los monopolios), que igualen a los ciudadanos al evitar ventajas desproporcionadas de índole intergeneracional, y que eviten que la esfera política pueda ser dominada por aquellos que ostentan un mayor poder económico (Rawls, 2001, p. 139). La democracia de propietarios no busca tras cada ciclo mercantil redistribuir la riqueza de acuerdo con un patrón que garantice un mínimo vital; por el contrario, busca que las mismas reglas estructurales de la sociedad establezcan de antemano parámetros de interacción fundamentados en la idea de la reciprocidad y la igualdad democrática.

\section{La constitucionalización de la democracia con propiedad privada}

Williamson (2013, p. 238) ha debatido sobre la forma como una democracia con propiedad privada podría ser aplicada en Estado Unidos. Su opinión es que dicha estructura requiere ser constitucionalizada a través de enmiendas que garanticen estabilidad. En su opinión, dichas enmiendas deben organizar el poder público para que se garantice una educación pública igualitaria, un ingreso mínimo a través de la dispersión de la propiedad y limitaciones a la participación política de las empresas.

El proyecto de Williamson resulta interesante al considerar una Constitución como la de Colombia, en la que expresamente se dispone que la forma de organización estatal es la de un Estado social y democrático de derecho. El Estado es denominado de derecho en cuanto se reconoce el imperio de la ley que establece que el ordenamiento jurídico opera como un límite al ejercicio del poder público de la autoridad pública, como una fuente de deberes de conductas y de prerrogativas para 
los ciudadanos y como los parámetros desde los cuales se administra justicia en la sociedad. Es social en cuanto reconoce unos derechos sociales y económicos que como mandatos programáticos buscan garantizar el acceso progresivo a niveles de bienestar cada vez más altos, con el fin de lograr la satisfacción de las necesidades básicas de todos los ciudadanos. Finalmente, es democrático en cuanto la soberanía reside en el pueblo, el cual puede depositarla en representantes elegidos democráticamente o ejercerla directamente a través de los mecanismos de participación ciudadana.

Debido a que nuestra constitución tiene la característica de definir expresamente el arquetipo de Estado, surge la duda de si la implementación de una democracia con propiedad privada requeriría un cambio de constitución. A continuación, se argumentará, aplicando la metodología de la interpretación constructiva de Dworkin, que la constitución contiene en sus principios y valores elementos suficientes para poder derivar de ella las exigencias del modelo de Estado en cuestión. Para esto se procederá en primera medida a explicar este método para luego aplicarlo al problema propuesto.

\section{La interpretación constructiva}

Las instituciones políticas que se erigen en un determinado momento histórico pueden ser vistas como valiosas instrumentalmente, por cuanto la mediación de un aparato estatal puede ser un mecanismo administrativo para realizar más eficientemente las finalidades que la moralidad universal exige de nosotros (Goodin, 1988, p. 663). Por ejemplo, si tenemos el deber de establecer un estado de cosas en el que todos los seres humanos gocen de las condiciones mínimas para llevar una vida digna, el sistema de Estados en el cual se organiza el planeta estará justificado si resulta ser una forma eficiente para descargar este deber, en comparación con formas alternativas de organización política o con una situación de anarquía. Esta visión parte de la idea de que existen unos valores universales preinstitucionales que se constituyen en los parámetros para evaluar la legitimidad y justificación de los sistemas políticos y jurídicos que reclaman autoridad sobre un área geográfica. Los valores y principios de justicia, según esta visión, no dependen de hechos históricos, sino de rasgos fundamentales constitutivos de la dignidad humana que tienen una importancia moral. $\mathrm{Si}$ las estructuras sociales en un momento histórico no garantizan la protección de los valores universales, son entonces obstáculos que deben ser removidos o modificados.

En contraste, las visiones no instrumentalistas sobre las instituciones sociales sostienen que las prácticas, hábitos e instituciones sociales no son simplemente mecanismos para implementar principios universales independientes, sino que son factores que determinan la formulación, el contenido, el alcance y la justificación de los 
valores que deben gobernar a una sociedad. Los constructos históricos (tradiciones, instituciones, prácticas sociales, sistemas jurídicos) no son solo mecanismos para implementar principios de justicia, sino que además son los datos primarios desde los que se debe iniciar la identificación de los valores y estándares de justicia por vía interpretativa.

De esta posición se origina un método elaborado por Dworkin (1986, p. 47) denominado constructivismo interpretativo. Interpretar es la actividad de atribuirle un propósito o significado a un objeto, y este último puede ser una ley, una obra de arte, una institución o una práctica social. Al identificar el propósito de una institución especificamos la finalidad que esta debe servir. Al tener acceso epistémico a esa finalidad podemos determinar de qué manera debe ser reformada la institución para que sirva mejor a su propósito.

El constructivismo interpretativo procede en tres etapas (Dworkin, 1986, p. 65). En una etapa preinterpretativa se deben determinar los contornos de la práctica que busca ser interpretada enlistando las convenciones, reglas, actitudes o instituciones que la conforman, con base en los consensos existentes al respecto. El intérprete no debe modificar el núcleo esencial de la práctica dando una descripción de esta que la desfigure o la torne en algo diferente. En una segunda etapa, se procede a atribuirle un propósito al objeto especificando los valores, bajo qué instancias y las finalidades que persigue. Finalmente, en la etapa post-interpretativa se debe establecer si es necesario reformar la práctica para que permita una realización más idónea de sus finalidades.

El método puede ser ejemplificado con la labor que adelanta el juez constitucional. El juez busca atribuir sentido a la ley promulgada por el Congreso. El juez no puede cambiarle ni una coma al texto aprobado mediante el procedimiento legislativo, pero sí puede identificar el propósito que debe servir a la luz de los principios y valores constitucionales. La labor del juez es entonces mostrar la ley en su mejor luz; es decir, debe determinar sus alcances interpretándola de la forma como mejor pueda realizar los valores y principios que fundamentan al Estado.

\section{La democracia de propietarios como la mejor interpretación del Estado social}

Thomas señala que muchos autores al hacer referencia a las diferencias entre el Estado social de derecho y la democracia de propietarios aplican el argumento del "máximo común denominador" (Thomas 2017, p. 191). Se trata de autores como O’neil o Weale (O’neil, 2012), para los cuales puede existir una continuidad entre las dos 
modelos de Estado, ya que comparten elementos comunes. La estrategia que utilizan es la de identificar todas esas instituciones y estructures que ambos sistemas deben implementar y determinar si aquellas institucionales adicionales de la democracia de propietarios están justificadas y pueden implementarse, y modificar así la estructura del Estado social. La estrategia es significativa porque muestra que, más que una oposición entre ambos sistemas, existe una posibilidad de progresión.

La crítica de Thomas se fundamenta, entre otras cosas, en que a pesar de que los dos sistemas pueden contener instituciones y reglas similares (por ejemplo, financiación estatal de las campañas políticas y un sistema universal de seguridad social) cada institución puede tener una función, un propósito y una justificación diferente en relación con la totalidad del modelo de Estado. Más precisamente, Thomas afirma que se trata de un error metodológico asumir que dos sistemas que comparten instituciones comunes son equiparables, puesto que esta forma de proceder ignora la perspectiva holística, según la cual el todo es el que determina la función de los elementos constitutivos. Así, ambos sistemas pueden compartir instituciones que socialicen la educación técnica y profesional, pero solo bajo una democracia de propietarios dicha política cumple la función de socializar el capital humano con miras a realizar el ideal de ciudadanía igualitaria.

El problema fundamental que puede señalarse en la objeción de Thomas es que no es claro por qué se debe proceder a través de arquetipos ideales sobre las formas de Estado, atribuyéndole a cada modelo una estructura y una finalidad predefinida, en lugar de proceder con un análisis interpretativo de los Estados sociales de derecho, tal cual los encontramos en nuestro momento histórico atribuyéndoles un propósito e implementado las reformas que lo harían operar desde la mejor luz. Más precisamente, al aplicar la metodología del constructivismo interpretativo podemos entender los Estados sociales de derecho como objetos de interpretación para identificar los valores y principios que lo gobiernan y las potenciales restructuraciones para que sea el mejor modelo.

Dicha estrategia está limitada, en virtud de que la etapa preinterpretativa solicita que no se ofrezca una imagen desfigurada del objeto de interpretación. No podemos transformar un modelo de Estado en cualquier otro a través de la simple interpretación porque tenemos la carga de definir los contornos del objeto de forma adecuada respetando su esencia. No obstante, al considerar aquellas instituciones que forman parte de la descripción arquetípica de la democracia de propietarios, se observa que no desnaturalizan por su implementación al Estado social de derecho. Por ejemplo, la dispersión de capital para evitar monopolios y garantizar a todos ingresos derivados de la propiedad no es una política institucional que afecte un pilar fundamental del Estado social. Lo mismo aplica a la medida de limitar por vía tributaria la transmisión testamentaria de ventajas desproporcionadas. En contraste, nótese que dicha 
medida riñe con el derecho a disponer irrestrictamente de la propiedad privada y con el rechazo a la intervención estatal en las transacciones entre adultos competentes propia del capitalismo del laissez-faire. Por este motivo, este último modelo no puede progresar interpretativamente hasta una democracia de propietarios, ya que son objetos de interpretación no equiparables.

De acuerdo con esto, no existe un motivo para aceptar la descripción arquetípica de Rawls, según la cual el Estado social tiene por objetivo la simple provisión de un mínimo vital con indiferencia del impacto que las distribuciones por encima de ese nivel de suficiencia humanitaria tienen sobre el valor de las libertades políticas. Los elementos que componen el Estado social de derecho pueden ser consistentemente interpretados como buscando el propósito de lograr la ciudadanía igualitaria. En la etapa posinterpretativa, buscaríamos cómo hacer de esta forma de organización estatal la mejor de su clase, para lo cual podríamos implementar las instituciones adicionales que le son propias a la democracia de propietarios.

La importancia de la estrategia de aplicar el constructivismo interpretativo a la presente discusión es que nos permite equiparar los dos sistemas, no solo en sus elementos y componentes institucionales, sino también en su finalidad y función; de esta manera, se superaría la crítica de Thomas sobre la falta de perspectiva holística. Esta forma de proceder resulta particularmente útil en Estados como Colombia, que incluyen la cláusula de "social". A diferencia del caso de Estados Unidos donde, como lo señala Williamson, la estabilidad y aplicación de una democracia de propietarios requiere enmiendas constitucionales, en Colombia las autoridades públicas pueden legislar, ejecutar políticas públicas y administrar justicia con miras a realizar el ideal de la igualdad democrática dentro de un modelo que satisfaga los requisitos de una democracia de propietarios.

\section{Conclusión}

La formulación de políticas y la persecución de finalidades públicas ya no recaen exclusivamente en el ejercicio del poder público o los efectos del mercado. Las redes de gobernanza muestran que existen formas horizontales de negociación entre actores formales e informales, que bajo patrones de interdependencia articulan sus acciones para dar forma al diseño y la ejecución de políticas públicas. Si bien el foro democrático deja de ser la instancia exclusiva para dar forma a los términos desde los cuales se despliega la autoridad del Estado, la necesidad de justificar a esta última exige la defensa de una ciudadanía igualitaria. La organización estatal debe tener este como uno de sus fines primordiales, teniendo en cuenta el impacto que las redes 
de gobernanza puedan tener en la vida pública de la comunidad. La importancia de hacer énfasis en la igualdad en la esfera pública se da no en virtud de un desconocimiento del complejo entramado de relaciones de poder que moldean las políticas públicas y que definen los contornos del sistema público de leyes, sino en razón al reconocimiento de que la dominación vertical de la administración pública frente al ciudadano es cualitativamente diferente. El derecho no es solo un mecanismo para controlar el comportamiento; es un sistema que reclama ser fuente legítima de derechos y deberes. Es esta aspiración a gobernar la racionalidad práctica de las personas la que resulta objeto de especial preocupación y lo que requiere la preclusión de cualquier forma de dominación.

Después de justificar el enfoque en el ámbito público, resulta relevante identificar modelos abstractos de organización del Estado, con miras a establecer estándares que nos permitan evaluar la operación real de las formas institucionalizadas de autoridad que nos gobiernan actualmente. Es importante identificar los valores y principios que esos modelos buscan realizar y hacer comparaciones entre distintas clases de Estado para determinar si son coherentes con los fines que persiguen. En el caso del Estado social, se le puede atribuir por estipulación la finalidad de mitigar la pobreza y asistir a las personas en momentos de infortunio. Acá se ha propuesto otra ruta: interpretativamente atribuirle la finalidad fundamental de garantizar la igualdad democrática.

Partiendo de esa atribución de valor y propósito a la cláusula "social" se deben adelantar las reformas y mejoras institucionales necesarias para mostrar dicho Estado "a su mejor luz". Las instituciones de la democracia de propietarios pueden ser un norte y pueden fijar los parámetros de justicia dentro de los cuales se debe ejercer el poder público. La ventaja de esta aproximación es que deja el aspecto reformista en el nivel interpretativo y no en el nivel del texto constitucional. La naturaleza rígida y el carácter estable propio de los textos constitucionales son consistentes con la adopción de interpretaciones que, sin desdibujarlos, muestren que estos pueden revestirse de muchos ropajes y que ninguno lucirá más ni deberá ser preferido que aquel que envuelve de justicia y legitimidad al poder público.

\section{Referencias}

Anderson, E. (1999). What is the point of equality? Ethics, 109, 287- 337.

Cohen.G.A. (2011). On the currency of egalitarian justice and other essays in political philosophy. New Jersey: Princeton University Press. 
Dagger, R. (2006) Neo-republicanism and the civic economy. Politics, Philosophy and Economics, 5, 151- 173.

Daniels, N. (1975). Reading Rawls. New York: Basic Books Publishers.

Dworkin, R. (1986). Law's Empire. Oxford: Hart Publishing.

Freeman, S. (2013). Property-owning democracy and the difference principle. Analyse and Kritik, (35), 9-36.

Goodin, R. (1988). What is so special about our fellow countrymen? Ethics, (98), 663 $-686$.

Koliba, C., Meek, J., Zia, A.y Mills, R. (2010). Governance network in public administration and public policy. Boca Ratón: Taylor and Francis.

Meade, J. (2016). Efficiency, Equality and the Ownership of Property. Nueva York: Routledge.

Nozick, R. (1974). Anarchy, state and utopia. Oxford: Blackwell Publishers.

O'Neill, M. (2012). Free (and Fair). Markets without capitalism: Political values, principles of justice, and property owning democracy. En M. O’Neill y T. Williamson (Eds.), Property owning democracy: rawls and Beyond (pp. 75100). Chichester: Blackwell Publishing

Rawls, J. (1993). Political liberalism. Nuev York: Columbia University Press.

Rawls, J. (1971). A theory of justice. Cambridge: Harvard University Press.

Rawls, J. (1999). The law of peoples. Cambridge: Harvard University Press.

Rawls, J. (2001). Justice as fairness: A restatement. Cambridge: Harvard University Press.

Thomas, A. (2017). Republic of equals: Pre-distribution and Property Owning Democracy. Oxford: Oxford University Press.

Sangiovanni, A. (2008). Justice and the priority of politics over morality. The Journal of Political Philosophy, (16), 1-28.

Sørensen, E. y Torfig, J. (2007). Theories of democratic network governance. Nueva York: Palgrave.

Williamson, T. (2013). Constitutionalizing property-owning democracy. Analyse and Kritik, (35), 237-253.

Weale, A. (2013). The property owning democracy versus the welfare state. Analyse and Kritik, (35), 37-54. 
